Ralph Dekoninck, Ad Imaginem. Statuts, fonctions et usages de l'image dans la littérature spirituelle jésuite du XVIIe siècle

Genève, Droz, coll. « Travaux du Grand Siècle », XXVI, 2005, 423 p.

Isabelle Saint-Martin

\title{
OpenEdition
}

Journals

Édition électronique

URL : http://journals.openedition.org/assr/5942

DOI : 10.4000/assr.5942

ISSN : $1777-5825$

Éditeur

Éditions de l'EHESS

Édition imprimée

Date de publication : 1 juin 2007

Pagination : 97-251

ISBN : 978-2-7132-2143-9

ISSN : 0335-5985

Référence électronique

Isabelle Saint-Martin, «Ralph Dekoninck, Ad Imaginem. Statuts, fonctions et usages de l'image dans la littérature spirituelle jésuite du XVIIe siècle », Archives de sciences sociales des religions [En ligne], 138| avril - juin 2007, document 138-31, mis en ligne le 11 septembre 2007, consulté le 21 septembre 2020. URL : http://journals.openedition.org/assr/5942 ; DOI : https://doi.org/10.4000/assr.5942

Ce document a été généré automatiquement le 21 septembre 2020.

(C) Archives de sciences sociales des religions 


\section{Ralph Dekoninck, Ad Imaginem. Statuts, fonctions et usages de l'image dans la littérature spirituelle jésuite du XVIIe siècle}

Genève, Droz, coll. « Travaux du Grand Siècle », XXVI, 2005, 423 p.

Isabelle Saint-Martin

1 Le titre de l'ouvrage laisse entrevoir un des aspects subtilement démontrés par l'auteur, les liens encore étroits entre le pensée de l'image développée au sein de la Compagnie de Jésus et la culture médiévale de l'imago qui prend sa source dans une conception de l'homme créé ad imaginem et similitudinem Dei. Ces liens rappelés, il reste à voir, et c'est précisément l'objet de ce livre, les évolutions ou transformations du statut des images dans l'univers de la Contre-Réforme qui s'affirme. Si l'homme est à l'image de Dieu, il lui faut encore gagner sa ressemblance par l'exercice de la connaissance et de l'union avec le divin, il est à cet égard une image en puissance que le missionnaire jésuite a charge de faire advenir. De quels secours lui sont alors les images mentales ou matérielles comme opérateurs de conversion? Précisons ici d'emblée que cette étude n'entend pas traiter de l'art jésuite en général ou de la question, abondamment débattue, de l'existence d'un style jésuite. Elle choisit au contraire un objet précis, la gravure et plus encore l'illustration, ainsi qu'un cadre géographique, la ville d'Anvers qui fut au XVII ${ }^{e}$ siècle un lieu privilégié de la production d'estampes, et retient une chronologie resserrée pour mettre en évidence les mutations qui s'opèrent. Le choix de la gravure, média de transmission et de diffusion, suggère une délimitation temporelle pertinente pour le corpus étudié. L'année 1585 marque à la fois le retour des jésuites dans la ville d'Anvers (ils en avaient été chassés en 1578) et le début de la réalisation des célèbres Evangelicae historiae imagines du père Nadal illustrés en majeure partie par les Wierix. En 1640, la parution d'un luxueux volume, l'Imago primi saeculi Societatis Jesu pour célébrer le premier centenaire de la Compagnie marque l'apogée d'une pratique de la littérature illustrée. L'analyse de ces quelques décennies est 
retracée sur deux plans: la défense qui s'attache aux principes théoriques et l'illustration qui passe en revue les principales éditions. Ces deux parties équilibrées structurent une recherche d'une grande cohérence et d'une grande finesse. Loin de n'être qu'une synthèse sur une littérature spirituelle certes fort riche pour cette période, mais sur laquelle on dispose déjà de nombreux travaux d'importance que l'auteur maitrise parfaitement, l'ouvrage propose une mise en perspective d'ensemble. En croisant les écrits des théoriciens et défenseurs des images et les pratiques des éditeurs et graveurs, il a pour ambition de faire émerger les contours d'une culture visuelle. En cela, si les bornes chronologiques et géographiques sont restreintes, le champ d'application demeure immense et ses implications sont d'une grande portée pour toute approche des arts visuels dans le christianisme. En effet, la première partie, consacrée aux théories de l'image afin de préciser statuts, fonctions et usages, met en rapport les écrits jésuites avec les traditions plus anciennes de la réflexion sur la théologie du visible. L'auteur repère trois types de sensibilité dans la manière d'utiliser les images et cherche à établir les liens entre l'économie augustinienne des trois puissances de l'âme (mémoire, intelligence, volonté), une forme de "trinité » de l'image marquée par trois modes d'êtres (trace, image, ressemblance) et les relations que l'on peut en dégager avec les trois fonctions de l'image selon Thomas d'Aquin ou Bonaventure (mnémonique, didactique et émotive) ou encore avec les trois étapes de la progression dans la contemplation mystique. Au terme de cette analyse, il cerne trois types de discours visuels (narration, symbole, allégorie) qui lui permettront d'ordonner la présentation des ouvrages de sa seconde partie autour de l'allegoria in factis, de l' allegoria in verbis et de l'allégorie mystique. Ceci le conduit à examiner au titre des «images narratives» les Figures de la Bible, les Evangelicae de Nadal, les ouvrages d'Andries et de Bourgeois pour les images de la Passion; puis pour les images symboliques, les catéchismes en images, le Veridicus de Jan David puis le Thesaurus de Sailly, la Via vitae d'Antoine Suquet, les livres de Pedro Bivero... Enfin les images dévotionnelles appellent l'étude du Paradisus de David, des Pia desideria de Hugo, des Amoris divini emblemata de Vaenius... Les gravures proposées tardivement (début XVII ) pour illustrer directement les Exercices spirituels vont emprunter ces différents genres, aux Pia Desideria et au Chemin de la Vie éternelle de Suquet notamment, et proposent comme une sorte de synthèse visuelle des plus importants volumes de la littérature spirituelle jésuite produits en une cinquantaine d'années à Anvers. Parmi les grandes questions soulevées par ce parcours, figure celle de l'ambiguïté du rapport à l'image dans la lecture mystique. Comment séduire par les sens sans détourner du Sens, sortir du paradoxe qui vise à accrocher par le regard pour mieux le détourner (p. 258). Déjà mise en évidence par P.-A. Fabre pour les Exercices ignatiens, et soulignée pour d'autres écrits par F. Lecercle entre autres, cette complexité du statut du visuel n'est pas éludée ici. R. Dekoninck en explore l'argumentation sans négliger toutefois de prendre au sérieux les images. Il sait se montrer attentif aux débats de nature philosophique comme à la forme et à la composition des gravures, mobilisant une formation de littérature et d'histoire de l'art. Ceci lui permet de repérer les mutations et de mettre en évidence une tendance à l'hypertrophie du texte, soucieuse de restreindre la polysémie de l'image. Celle-ci finit par perdre de son autonomie et l'on passe, notamment pour les images symboliques, d'une forme d'«imagerie à commenter" à ce qui devient une littérature plus ou moins illustrée (p. 327). L'éducation du regard chère à la pédagogie jésuite appelle une lecture contrôlée de l'image. La valeur de celle-ci n'est plus jugée en termes de ressemblance avec un 
modèle mais pour ses effets produits sur le spectateur. Le souci est désormais moins celui de la vérité de l'image que celui de son efficacité qui résulte de son éloquence sensible

À la croisée de la théologie, de la philosophie, de l'histoire de l'art, de l'histoire du livre et de l'histoire culturelle au sens large, la démonstration est d'une grande cohérence et l'écriture demeure d'une parfaite clarté pour des sujets souvent complexes. Le lecteur est conduit d'une main ferme et suit un développement rigoureusement construit. La maitrise de l'argumentation rhétorique, que traduit la structure remarquable du plan, et la limpidité du style contribuent au plaisir de la lecture malgré la densité de l'ouvrage. Certes l'ampleur du sujet traité est telle que l'on pourrait avoir, non des regrets, mais le souhait de discuter plus avant tel ou tel point de détail (de relever par exemple que la notion de componction est déjà présente dans la lettre de Grégoire à Serenus, p. 113). On aimerait aussi en savoir plus sur les pratiques de ces lectures dévotes et les «braconnages " éventuels, pour reprendre l'expression de Michel de Certeau (L'Invention du quotidien), auxquelles elles ont pu conduire. En effet si pertinente que soit la présentation typologique de la seconde partie, ce découpage des titres selon les trois fonctions (mémoriale, intellective, spirituelle) ne doit pas faire oublier que les usages de ces éditions ont pu mener à bien des recompositions posant sur chacune de ces catégories un regard susceptible d'être animé par ces trois aspects.

En introduction, Ralph Dekoninck situait son propos, à la suite de P.-A. Fabre et A. Romano, dans une phase de la recherche qui «s'attache moins à la compréhension de l'histoire de la Compagnie qu'à une meilleure connaissance de notre modernité via la Compagnie ». En mettant en évidence le souci de créer un système de communication efficace, reposant sur des images qui ne cherchent plus tant à présenter qu'à représenter, il montre comment les jésuites ont contribué à l'émergence d'une nouvelle culture visuelle. 